\title{
Audiodescrição em Cinema e Televisão: uma ponte que conduz à inclusão cultural da pessoa com deficiência visual
}

\author{
Descripción de audio en la Televisión y el Cine: un puente que conduce a \\ la inclusión cultural de las personas con discapacidad visual
}

\author{
Audio description in movie theater and Television: a bridge that leads to \\ cultural inclusion of persons with visual impairment
}

\author{
João Batista Santana Correia ${ }^{1}$
}

\begin{abstract}
Resumo
A partir da divulgação dos dados referentes ao Censo realizado em 2010 pelo Instituto Brasileiro de Geografia e Estatística - IBGE - afirmando que o Brasil possui 18,60\% de sua população formada por pessoas cegas ou com baixa visão e a constatação de que a produção midiática baseia-se em imagens, como é o caso do Cinema e da Televisão, a audiodescrição (AD) apresenta-se com um recurso de tecnologia assistiva (TA) de acessibilidade capaz de oportunizar às pessoas com deficiência visual as condições mínimas necessárias para consumirem conteúdos audiovisuais em situação de equidade com as demais pessoas. Este estudo, apoiado nas produções teóricas de Charles S. Peirce, Roman Jakobson e Lúcia Santaella e utilizando-se da metodologia qualitativa de cunho bibliográfico, buscou identificar e descrever a audiodescrição como uma modalidade intersemiótica, isto é, a tradução de uma linguagem para outra linguagem - visual para a verbal, como uma ferramenta de acessibilidade comunicacional e informacional que pode conduzir à inclusão sociocultural das pessoas com deficiência visual.

Palavras-Chave: Audiodescrição, comunicação, inclusão, pessoa com deficiência, tradução intersemiótica.
\end{abstract}

\section{Resumen}

A partir de la divulgación de datos sobre el censo realizado en 2010 por el Instituto Brasileño de Geografía y Estadística -IBGE - manifestando que Brasil tiene 18,60\% de su problación formada por personas que son ciegas o con baja visión y la comprensión de que la producción de los medios de comunicación se base en imágenes, como el Cine y la Televisión, descripción de audio (AD) se presenta con un recurso de tenología de asistencia (TA) la accesibilidad capaz de crear oportunidades para las personas con discapacidad visual de las condiciones mínimas necesarias para consumir contenidos. audiovisuales situación de equidad com los demás. Este estudio, com el apoyo de las produciones de Charles S. Peirce, Roaman Jakobson y Lúcia Santaella y el uso de la metodología cualitativa de la naturaleza bibliográfica, trató de identificar y describir la descripsión de audio como un modo de intersemiótico, es decir, la traducción de um idioma a otro idioma, visual a la calificación verbal como herramienta de accesibilidad comunicacional e informativa que puede conducir a la inclusión sociocultural de las personas con descapacidad visual.

Palabras clave: Descripción de audio, de comuncación, de inclusión, las personas com descapacidad, traducción intersemiótica.

Abstract

${ }^{1}$ Universidade Federal do Pampa (UNIPAMPA). E-mail: joaobatistadp@globo.com. 
From the disclosure of data on the census conducted in 2010 by the Brazilian Institute of Geography and Statistics - IBGE - stating that Brazil has $18.60 \%$ of its population made up of people who are blind or have low vision and the realization that media production is based in images, such as the movie theater and Television, audio description (AD) is presented with an assistive technology resource (TA) accessibility able to create opportunities for people with visual impairment the minimum conditions necessary to consume audiovisual content equity situation with others. This study, supported by the theoretical productions of Charles S. Peirce, Roman Jakobson and Lúcia Santaella and using the qualitative methodology of bibliographic nature, sought to identify and describe the audio description as a intersemiotic mode, that is, the translation from one language to another language - visual to verbal as a communicational and informational accessibility tool that can lead to socio-cultural inclusion of persons with visual impairment.

Keywords: audio description, communication, inclusion, peaple with disabilities, intersemiotic translation.

\section{Introdução}

O Censo Demográfico realizado pelo Instituto Brasileiro de Geografia e Estatística IBGE, em 2010, apontou que 18,60\% da população brasileira possuem algum tipo de deficiência visual e, destes, 8,46\% apresentam deficiência visual severa (OLIVEIRA, 2012).

O Decreto $n^{\circ}$ 5.296/2004 define as condições que enquadram a ocorrência de cegueira e de baixa visão:

Cegueira, na qual a acuidade visual é igual ou menor que 0,05 no melhor olho, com a melhor correção óptica; a baixa visão, que significa acuidade visual entre $0,3 \mathrm{e}$ 0,05 no melhor olho, com a melhor correção óptica; os casos nos quais a somatória da medida do campo visual em ambos os olhos for igual ou menor que $60^{\circ}$; ou a ocorrência simultânea de quaisquer das condições anteriores (BRASIL, 2004).

A partir desta definição e da evidência que todos os produtos televisivos e cinematográficos utilizam a linguagem imagética, busca-se identificar e descrever a audiodescrição com um recurso de tecnologia assistiva - TA, capaz de promover a acessibilidade ao proporcionar o acesso por meio da tradução intersemiótica ou transmutação, isto é, a tradução de conteúdos imagéticos em palavras, de não verbal em verbal, oportunizando, assim, que pessoas cegas ou com baixa visão possam interpretar, compreender e interagir com o que acontece na tela.

Através do estudo produzido por Franco; Silva (2010) destaca-se, resumidamente, que a audiodescrição (AD) foi criada a partir da dissertação de mestrado de Gregory Frazier, apresentada na década de 1970 nos Estados Unidos, no entanto, a pesquisa foi colocada em prática pelo casal Margaret Rockwell e Cody Pfanstiehl. Margaret, pessoa com deficiência visual, foi fundadora do grupo de ledores The Metropolitan Washington Ear. Pela experiência, o casal foi pioneiro na atividade de traduzir imagens em palavras ao efetuar a audiodescrição da uma peça teatral Major Barbara em 1981. Posteriormente, o casal fez audiodescrição do acervo de museus, de parques e de monumentos norte-americanos. Em 
RELACult - Revista Latino-Americana de Estudos em Cultura e Sociedade

Revista Latinoamericana de Estudios en Cultura y Sociedad | Latin American Journal of Studies in Culture and Society V. 03, $\mathrm{n}^{\mathbf{0}} 01$, jan-abr., 2017, p. 26-42 | relacult.claec.org e-ISSN 2016/Atual: 2525-7870 | e-ISSN 2015/2016: 2447-018X

1982 a audiodescrição chegou aos canais de Televisão dos Estados Unidos por intermédio da série American Playhouse. No ano de 1992, a WGBH deu início ao projeto Motion Picture Access (MoPix) que tinha por objetivo colocar a audiodescrição nas salas de cinema, como recurso de acessibilidade que contemplasse as pessoas com deficiência visual, em circuito comercial. A primeira produção cinematográfica a receber a $\mathrm{AD}$ foi o filme $O$ Chacal.

Ainda na década de 1980, a AD passou a integrar as produções audiovisuais de outros países como a Inglaterra, Espanha, Japão e Argentina.

No Brasil, a AD estreou em 2003, por meio do Festival Internacional de Filmes sobre Deficiência; em 2005, aconteceu o lançamento do filme Irmãos que é considerado o primeiro filme em DVD em escala comercial a oferecer uma faixa adicional de áudio com audiodescrição; em 2007, foi a vez de uma peça teatral, denominada Andaime utilizar o recurso de audiodescrição; em 2008, a AD chega à Televisão com uma peça publicitária da marca Natura e em 2009 a AD marcava presença na ópera Sansão e Dalila.

A audiodescrição, por ser um fator determinante na promoção da acessibilidade comunicacional das pessoas com deficiência visual, poderia ser contemplada nas políticas públicas transversais garantidoras do direito constitucional de todo o cidadão de ter acesso à comunicação social e a cultura por meio da Televisão e do Cinema em equidade com as demais pessoas.

Nesta perspectiva, fica estabelecida a possibilidade de empoderamento de um segmento social "minoritário" formado por milhões de brasileiros que muitas vezes sentem-se vilipendiados e impotentes diante do poderio econômico e midiático de empresas que deveriam prover de audiodescrição seus produtos audiovisuais.

Por outro lado, a audiodescrição apresenta-se com uma profissão, pois permite que roteiristas, produtores, audiodescritores, redatores, pessoas com deficiência visual que prestam consultoria, pesquisadores, professores de audiodescrição, enfim, inúmeras pessoas ligadas direta ou indiretamente à audiodescrição são responsáveis pela inclusão sociocultural das pessoas com deficiência através dos filmes veiculados na TV e no Cinema.

Após sua primeira aparição como objeto de investigação científica, ao ser abordada em uma dissertação, a audiodescrição somente veio a ser tratada cientificamente na década de 1990 por meio das pesquisas apoiadas pela American Foundation for the Blind (AFB).

Na Inglaterra, a maioria dos estudos contou com o apoio do Royal National Institute of Blind People (RNIB) e aconteceu como parte integrante do projeto Audio Described Television (AUDETEL), um consórcio multinacional formado para investigar os diversos aspectos (técnicos, logísticos, artísticos, etc.) envolvidos na transmissão de programas audiodescritos pela TV na Europa. Muitos desses estudos 
deram origem a artigos publicados em periódicos especializados ligados à questão da deficiência visual como o Journal of Visual Impairment \& Blindness (EUA) e o British Journal of Visual Impairment (Inglaterra) (FRANCO; SILVA, 2010, p. 27).

Em nosso país, as pesquisas acadêmicas a respeito da audiodescrição estão sendo desenvolvidas, principalmente, pelas "universidades federais da Bahia, de Pernambuco, Minas Gerais e pela Universidade Estadual do Ceará” (FRANCO; SILVA, 2010, p. 33).

De acordo com Franco e Silva (2010), a produção acadêmica sobre audiodescrição é ainda incipiente, destacando-se alguns grupos de pesquisa que são pioneiros no Brasil em discutir essa temática, a exemplo dos grupos TRAMAD (Tradução, Mídia e Audiodescrição) que foi o primeiro a surgir, em 2004, coordenado pela Dra. Eliana Franco da Universidade Federal da Bahia (UFBA), seguido pelo LEAD (Legendagem e Audiodescrição), coordenado pela Dra.Vera Lúcia Santiago Araújo, da Universidade Estadual do Ceará (UECE).

Quando se mencionam os estudos e as pesquisas realizadas na área da audiodescrição desde seus primórdios, torna-se fundamental ressaltar a participação dos meios de comunicação, Televisão e Cinema norte-americanos que, além de incentivar, adotaram a audiodescrição em suas produções audiovisuais permitindo, assim, que um número crescente de pessoas com deficiência visual consuma seus produtos.

No Brasil, a Norma Complementar do Ministério das Comunicações n ${ }^{\circ}$ 01/2006 que trata sobre os recursos de acessibilidade para as pessoas com deficiência nas programações veiculadas nos serviços de radiodifusão de sons e imagens e de retransmissão de Televisão. Esta legislação determina que as empresas detentoras de "concessão ou permissão" do Governo Federal para “explorar o Serviço de Radiodifusão de Sons e Imagens e o Serviço de Retransmissão de Televisão e do Serviço de Repetição de Televisão ancilar ao Serviço de Radiodifusão de Sons e Imagens" devem proporcionar o recurso de audiodescrição "em língua Portuguesa, devendo ser transmitida através do Programa Secundário de Áudio (SAP), sempre que o programa for exclusivamente falado em português” (BRASIL, 2006).

As produções cinematográficas, assim como as das Emissoras de Televisão, estão regidas por legislação e, no caso do Cinema, é a Instrução Normativa 116, de 18 de dezembro de 2014, que normatiza os critérios básicos de acessibilidade que devem ser seguidos pelos produtores de audiovisuais que recebem financiamentos oriundos do poder público federal e são geridos pela Agência Nacional do Cinema - ANCINE (BRASIL, 2014).

A legislação sobre a acessibilidade comunicacional, tanto da Televisão quanto a do Cinema, está em consonância com o que determina a Convenção Sobre os Direitos das Pessoas com Deficiência e seu Protocolo Facultativo, assinados em Nova York, em 30 de 

e-ISSN 2016/Atual: 2525-7870 | e-ISSN 2015/2016: 2447-018X

março de 2007 e que foram incorporadas à legislação brasileira pelo Decreto no 6.949 de 25 de agosto de 2009 que, entre outros, reconhece que a deficiência é um conceito em evolução e resultante da relação da pessoa com deficiência com as barreiras físicas ou atitudinais presentes em um determinado ambiente. No artigo 30 desse documento, que trata da Participação na vida cultural e em recreação, lazer e esporte, os países signatários se comprometem em reconhecer o direito das pessoas com deficiência de participar da vida cultural, em igualdade de oportunidades com as demais pessoas e em adotar as medidas necessárias para que as pessoas com deficiência possam “[...] ter acesso a programas de televisão, cinema, teatro e outras atividades culturais, em formatos acessíveis [...]" (BRASIL, 2009, grifo nosso).

A lei $n^{\circ} 13.146 / 2015$ considera tecnologia assistiva - TA, os "recursos práticas e serviços que objetivam promover a funcionalidade, relacionada à atividade e à participação da pessoa com deficiência" objetivando, desta forma, "a sua autonomia, independência, qualidade de vida e inclusão social”. (BRASIL, 2015, grifo nosso).

Para Júnior e Filho (2010) a

Audiodescrição (AD) é um dispositivo linguístico desenvolvido para atender as necessidades das pessoas com deficiência visual (PcDVs), quer cegas ou com baixa visão, favorecendo-lhes a acessibilidade a produtos (audio)visuais e contribuindo, assim, para o seu empoderamento, especialmente como fruidoras de arte (JÚNIOR; FILHO, 2016, p. 23).

\section{Audiodescrição, uma transmutação ou tradução intersemiótica}

A audiodescrição pode ser compreendida também como uma transmutação ou tradução intersemiótica, isto é, a transformação de uma linguagem imagética em uma linguagem verbal.

$\mathrm{Na}$ teoria defendida por Jakobson (2007) existem três maneiras distintas para se interpretar um signo verbal: "Ele pode ser traduzido em outros signos da mesma língua, em outra língua, ou em outro sistema de símbolos não-verbais", ao que o autor faz corresponder, respectivamente três classificações: A primeira espécie de signos verbais corresponde a "tradução intralingual ou reformulação (rewor-ding)", a segunda é a" tradução iriterlingual ou tradução propriamente dita" e a terceira e a mais importante para este estudo a "tradução intersemiótica ou transmutação", que "consiste na interpretação dos signos verbais por meio de sistemas de signos não-verbais" (JAKOBSON, 2007, p. 64-65). 
$\mathrm{Na}$ prática, a audidescrição consiste em uma pessoa vidente acompanhar uma produção audiovisual; redigir um texto com os detalhes presentes no vídeo ou na tela de cinema; alguém vai gravar ou fazer a narração "ao vivo"; a pessoa com deficiência recebe esta mensagem pela audição e cria em sua mente os elementos contextuais como o figurino dos personagens, o cenário, a marcação de tempo e espaço presentes na produção audiovisual. Esse detalhamento permite que a pessoa cega ou com baixa visão possa se conectar e interagir com o produto.

Todos os detalhes envolvendo a audiodescrição poderiam ser resumidos no seguinte: "Por seu caráter de transmutação de signo em signo, qualquer pensamento é necessariamente uma tradução" (PLAZA, 2008, p. 18). Sendo assim, "quando pensamos traduzimos aquilo que temos presente à consciência, quer sejam imagens, sentimentos e concepções (que, aliás, já são signos ou quase signos) em outras representações que servem como signo" (PLAZA, 2008, p. 18).

Segundo Pierce (2000), "um signo ou representamen é aquilo que, sob certo aspecto ou modo, representa algo para alguém. Dirigir-se a alguém, isto é, criar na mente dessa pessoa um signo equivalente, ou talvez um signo mais desenvolvido". Esse autor denomina

\footnotetext{
O signo assim criado como interpretante do primeiro signo. O signo representa alguma coisa, seu objeto. Representa esse objeto não em todos os seus aspectos, mas com referência a um tipo de ideia. 'Ideia' deve ser aqui entendida num certo sentido platônico, muito comum no falar cotidiano; refiro-me àquele sentido em que dizemos que um homem pegou a ideia de outro homem; em que quando o homem relembra o que estava pensando anteriormente, relembra a mesma ideia e, em que, quando um homem continua a pensar alguma coisa, digamos por um décimo de segundo, na medida em que o pensamento continua conforme consigo mesmo durante este tempo, isto é, a ter um conteúdo similar, é a mesma ideia e não, em cada instante deste intervalo, uma nova ideia. (PEIRCE, 2000, p. 55).
}

Mas como se dá a apreensão e a compreensão do mundo pelo ser humano? Santaella (2005) afirma que Peirce se debruçou por anos na solução desta questão, talvez a mais antiga, da filosofia. Para a autora, tudo indica que ele tenha se utilizado da fenomenologia para chegar a seguinte conclusão:

Tudo que a nossa mente é capaz de apreender, tudo que aparece à consciência, assim o faz numa gradação de três e não mais do que três elementos formais: (1) qualidade de sentimento, (2) ação e reação e (3) mediação. (SANTAELLA, 2005, p. 14-15).

Mas, a autora (2005, p. 15) reforça que os modos de apreensão dos fenômenos quer seja o fenômeno físico, psíquico, real ou imaginado pode ser expresso como: (1) qualidade, 
(2) reação e (3) representação. A partir da classificação dos fenômenos, Santaella (2005) elucida que:

\footnotetext{
Peirce esvaziou os termos de qualquer conteúdo material, reduzindo-os à sua natureza puramente lógica. Daí as categorias passaram a ser designadas por: (1) primeridade $=$ mônada, $(2)$ secundidade $=$ reação diádica e (3) terceridade $=$ relação triádica" (SANTAELLA, 2005, p. 15).
}

Santaella (2005) argumenta que "o que define basicamente a natureza da linguagem verbal é o seu poder conceitual, a ponto de podermos afirmar que o verbal é reino da abstração". E “isso corresponde com exatidão às características daquilo que Peirce definiu como signo simbólico, o universo das mediações e das leis" (SANTAELLA, 2005, p. 19).

No que diz respeito à linguagem visual, "sua característica primordial está na insistência com que as imagens singulares, aqui e agora, se apresentam à percepção" (SANTAELLA, 2005, p. 19).

Para Santaella (2005, p. 19) "ver é estar diante de algo, mesmo que esse algo seja uma imagem mental ou onírica, pois o que caracteriza uma imagem é sua presença, estar presente, tomando conta da nossa apreensão". Por este raciocínio, pode-se inferir que a linguagem visual apreendida pelo audiodescritor pode ser transmutada por meio da linguagem verbal que chega ao ouvinte com deficiência visual através da linguagem sonora transformando-se na mente do "(tele)espectador" em linguagem visual, novamente.

Por meio da tradução intersemiótica a pessoa cega ou com baixa visão cria uma imagem mental que permite a informação, a contextualização e a interação com o que está acontecendo na tela do Cinema ou da Televisão. Esta imagem, conforme a pesquisadora, pertence ao universo da secundidade e é, portanto, considerada por sua característica figurativa e referencial um signo indicial.

Por sua vez, como diz Santaella (2005), a linguagem sonora possui um referencial muito frágil em razão do som não possuir o poder de representar algo que esteja fora dele. A autora aponta que a linguagem sonora "pode no máximo, indicar sua própria proveniência, mas não tem a capacidade de substituir algo, de estar no lugar de uma outra coisa que não seja ele mesmo". E acrescenta que "essa falta de capacidade referencial do som é compensada pelo seu alto poder de sugestão, o que fundamentalmente o coloca no universo icônico [...]" (SANTAELLA, 2005, p. 19).

Embora não seja foco deste trabalho, um aspecto que deve ser observado com relação à audiodescrição: Imagina-se, neste estudo, que a linguagem escrita utilizada pelo redator e a 
linguagem verbal usada pelo audiodescritor e que chegam aos ouvidos da pessoa com deficiência visual através da linguagem sonora, são formadas a partir de uma combinação e seleção de palavras conhecidas por ambos, isto é, que invariavelmente venha fazer parte do vocabulário da pessoa com deficiência visual. Em outras palavras, este estudo não se detém em avaliar a existência de "afasia" (JAKOBSON, 2007) na relação mantida pelo audiodescritor enquanto emissor e a pessoa com deficiência visual como receptor da mensagem.

Para Jakobson (2007, p. 39-40) "todo o signo linguístico implica em dois modos de arranjo": O primeiro é a combinação e a outra é a seleção. Na combinação "todo signo é composto de signos constituintes e/ou aparece em combinação com outros signos." O autor esclarece que "qualquer unidade linguística serve, ao mesmo tempo, de contexto para unidades mais simples e/ou encontra seu próprio contexto em uma unidade linguística mais complexa". E, na seleção, os "termos alternativos" implicam "na possibilidade de substituir um pelo outro, equivalente ao primeiro num aspecto e diferente em outro" (JAKOBSON, 2007, p. 39-40). O mesmo autor afirma que "as línguas diferem essencialmente naquilo que devem expressar, e não naquilo que podem expressar" e reforça sua argumentação dizendo que "o nível cognitivo da linguagem não só admite mas exige a interpretação por meio de outros códigos, a recodificação, isto é, a tradução" (JAKOBSON, 2007, p. 70).

\section{Arcabouço Legal}

A Norma Complementar $n^{\circ} 1 / 2006$ tem por objetivo:

Complementar as disposições relativas ao serviço de radiodifusão de sons e imagens e ao serviço de retransmissão de televisão, ancilar ao serviço de radiodifusão de sons e imagens, visando tornar a programação transmitida ou retransmitida acessível para pessoas com deficiência, conforme disposto na Lei no 10.098, de 19 de dezembro de 2000 e no Decreto no 5.296, de 2 de dezembro de 2004, alterado pelo Decreto $\mathrm{n}^{\circ}$ 5.645, de 28 de dezembro de 2005 (BRASIL, 2006).

O mesmo documento classifica acessibilidade como a "condição para utilização, com segurança e autonomia, dos serviços, dispositivos, sistemas e meios de comunicação e informação, por pessoa com deficiência auditiva, visual ou intelectual" e a audiodescrição como:

Narração, em língua portuguesa, integrada ao som original da obra audiovisual contendo descrições de sons e elementos visuais e quaisquer informações adicionais que sejam relevantes para possibilitar a melhor compreensão desta por pessoas com deficiência visual e intelectual (BRASIL, 2006). 

assegura que:

O Artigo 17 da Lei $\mathrm{n}^{\mathrm{o}} 10.098$ de 19 de dezembro de 2000, em seu capítulo VII,

O Poder Público promoverá a eliminação de barreiras na comunicação e estabelecerá mecanismos e alternativas técnicas que tornem acessíveis os sistemas de comunicação e sinalização às pessoas portadoras de deficiência sensorial e com dificuldade de comunicação, para garantir-lhes o direito de acesso à informação, à comunicação, ao trabalho, à educação, ao transporte, à cultura, ao esporte e ao lazer (BRASIL, 2000, grifo nosso).

A mesma Lei, em seu Artigo $2^{\circ}$, inciso II, define barreira como:

Qualquer entrave, obstáculo, atitude ou comportamento que limite ou impeça a participação social da pessoa, bem como o gozo, a fruição e o exercício de seus direitos à acessibilidade, à liberdade de movimento e de expressão, à comunicação, ao acesso à informação, à compreensão, à circulação com segurança, entre outros [...]. (BRASIL, 2000)

E define barreira nas comunicações e na informação como "qualquer entrave, obstáculo, atitude ou comportamento que dificulte ou impossibilite a expressão ou o recebimento de mensagens e de informações por intermédio de sistemas de comunicação e de tecnologia da informação" (BRASIL, 2000).

A Instrução Normativa $n^{0}$ 116, de 18 de dezembro de 2014, que "dispõe sobre as normas gerais e critérios básicos de acessibilidade a serem observados por projetos audiovisuais financiados com recursos públicos federais geridos pela ANCINE [...]" (BRASIL, 2014) em seu Artigo $1^{\circ}$, resolve que "todos os projetos de produção audiovisual financiados com recursos públicos federais geridos pela ANCINE deverão contemplar nos seus orçamentos serviços de legendagem descritiva, audiodescrição e LIBRAS - Língua Brasileira de Sinais" (BRASIL, 2014, grifo nosso).

A Lei $n^{\circ}$ 13.146, de 6 de julho de 2015, que Institui a Lei Brasileira de Inclusão da Pessoa com Deficiência (Estatuto da Pessoa com Deficiência), em seu artigo $3^{\circ}$, ratifica a necessidade de remoção de barreiras, dentre as quais cita aquelas de ordem comunicacional e informacional.

Acredita-se que a Convenção Internacional sobre os Direitos das Pessoas com Deficiência, assinada em Nova York, em 2007, e promulgada como Emenda à Constituição Federal do Brasil pelo Decreto $\mathrm{n}^{\mathrm{o}}$ 6.949, de 25 de agosto de 2009, constitui-se como um "divisor de águas" pois reconhece que:

A deficiência é um conceito em evolução e que a deficiência resulta da interação entre pessoas com deficiência e as barreiras devidas às atitudes e ao ambiente que 
impedem a plena e efetiva participação dessas pessoas na sociedade em igualdade de oportunidades com as demais pessoas (BRASIL, 2009).

Partindo-se do pressuposto que a inclusão da pessoa com deficiência se concretiza a medida que ela passa a exercer plenamente sua cidadania, isso equivale a dizer que tenha a sua disposição as condições mínimas e favoráveis para usufruir de todos os bens sociais, econômicos e culturais de sua coletividade em equidade de oportunidades com as demais pessoas. Para Sassaki (1997) a inclusão social consiste em efetivar "o processo pelo qual a sociedade se adapta para poder incluir em seus sistemas sociais gerais as pessoas com deficiência (além de outras) e, simultaneamente, estas se preparam para assumir seus papeis na sociedade" (SASSAKI, 1997, p. 39).

Na mesma direção, a Associação Brasileira de Normas Técnicas - ABNT - NBR 15290, editada em 31 de outubro de 2005 e que entrou em vigor no dia 30 de novembro do mesmo ano, tem por objetivo estabelecer as

Diretrizes gerais a serem observadas para acessibilidade em comunicação na televisão, consideradas as diversas condições de percepção e cognição, com ou sem a ajuda de sistema assistivo ou outro que complemente necessidades individuais (ABNT, 2005, p.1, grifo nosso).

Nesse documento, a acessibilidade consiste na "possibilidade e condição de alcance para utilização do meio físico, meios de comunicação, produtos e serviços, por pessoa com deficiência" e "barreira à comunicação como qualquer entrave ou obstáculo que dificulte ou impossibilite a expressão ou o recebimento de mensagens por intermédio dos meios ou sistemas de comunicação, sendo ou não de massa [...]" (ABNT, 2005, p. 2). A legislação não menciona o termo "audiodescrição", mas identifica a atividade de descrição em áudio de imagens e sons como a

Narração descritiva em voz de sons e elementos visuais-chave - movimentos, vestuário, gestos, expressões faciais, mudanças de cena, textos e imagens que apareçam na tela, sons ou ruídos não literais - desapercebidos ou incompreensíveis sem o uso da visão (ABNT, 2005, p. 2).

\section{Breve resgate histórico do atendimento prestado às pessoas com deficiência no Brasil}

Com base nos estudos realizados por Lanna Júnior (2010), faz-se um breve resgate no que diz respeito ao atendimento das pessoas com deficiência em nosso país. 
Como um dos primeiros atos registrados na direção do "atendimento" das pessoas com deficiência no Brasil está a fundação do Hospital São Lázaro, no Rio de Janeiro, que recebia e confinava as pessoas leprosas.

Segundo Lanna Júnior (2010), o Decreto $n^{\circ}$ 82, de 18 de julho de 1841, determinou a fundação do primeiro hospital "destinado privativamente para o tratamento de alienados" o Hospício Dom Pedro II, vinculado à Santa Casa de Misericórdia, instalado no Rio de Janeiro. Dois anos depois, em 1854, o Brasil foi pioneiro na América Latina ao colocar em funcionamento o Imperial Instituto dos Meninos Cegos e em 1856, o Imperial Instituto dos Surdos-Mudos.

O primeiro trabalho científico realizado no Brasil, em 1900, que abordava a temática "idiotia" foi a monografia sobre educação e o tratamento médico pedagógico dos idiotas, de autoria do médico Carlos Eiras.

Ainda, de acordo com Lanna Júnior (2010, p. 23), o Imperial Instituto dos Meninos Cegos teve seu nome modificado, em 1889, para Instituto dos Meninos Cegos e, em 1890, para Instituto Nacional dos Cegos. Finalmente, em 1891, recebeu a denominação que conserva até hoje: Instituto Benjamin Constant (IBC). O Imperial Instituto dos Surdos-Mudos chamou-se Instituto dos Surdos-Mudos até 1957, quando recebeu o nome atual: Instituto Nacional de Educação de Surdos (INES).

Lanna Júnior (2010, p. 29) destaca o ano de 1950 como marco da história das pessoas cegas em razão de ter ocorrido nesse ano a autorização por parte do Conselho Nacional de Educação para que estudantes cegos ingressassem nas faculdades de Filosofia.

Em 1954, no Rio de Janeiro, foi fundada a primeira Associação dos Pais e Amigos dos Excepcionais (APAE).

Da década de 1950 até meados de 1990, o atendimento às pessoas com deficiência esteve restrito a instituições especializadas. A partir da década de 1990, o Brasil ingressa em um movimento internacional pela inclusão das pessoas com deficiência na sociedade, de modo que estas exerçam o direito de acesso a todos os bens e serviços em condições de igualdade com as demais pessoas. Tal movimento se baseia no conceito "social" de deficiência (DINIZ; BARBOSA; SANTOS, 2009), que considera a deficiência como produção da sociedade ao interpor barreiras à participação de pessoas que apresentam diferenças específicas e exige o provimento de recursos e serviços que assegurem a equidade como única forma de alcançar a igualdade de direitos.

\section{Pessoa com deficiência}


RELACult - Revista Latino-Americana de Estudos em Cultura e Sociedade

Revista Latinoamericana de Estudios en Cultura y Sociedad | Latin American Journal of Studies in Culture and Society V. 03, no 01, jan-abr., 2017, p. 26-42 | relacult.claec.org e-ISSN 2016/Atual: 2525-7870 | e-ISSN 2015/2016: 2447-018X

Conforme Araújo (2011), conceito de deficiência vem passando por inúmeras alterações após a promulgação do Decreto Legislativo no 186, de 09 de julho de 2008, nos termos do $\S 3^{\circ}$ do art. $5^{\circ}$ da Constituição Federal que tem valor de emenda constitucional e reconhecida com tal em $1^{\circ}$ de agosto de 2008 e pelo Decreto $n^{\circ} 6.949$, de 25 de agosto de 2009, que "trouxe ao ordenamento jurídico brasileiro novo conceito de pessoa com deficiência, dessa vez de status constitucional e, assim, com eficácia revogatória de toda a legislação infraconstitucional que lhe seja contrária" (ARAÚJO, 2011, p. 2).

A Lei n ${ }^{\circ}$ 13.146, de 6 julho de 2015, que institui a Lei Brasileira de Inclusão da Pessoa com Deficiência (Estatuto da Pessoa com Deficiência) em seu Artigo $2^{\circ}$ considera-se pessoa com deficiência "aquela que tem impedimento de longo prazo de natureza física, mental, intelectual ou sensorial, o qual, em interação com uma ou mais barreiras, pode obstruir sua participação plena e efetiva na sociedade em igualdade de condições com as demais pessoas" (BRASIL, 2015, grifo nosso).

\subsection{Pessoa com deficiência e as denominações recebidas ao longo da História}

Ao longo da História o indivíduo com deficiência já foi chamado, considerado e identificado, pejorativamente, como "anormal, retardado, débil, enfermo, inválido, incapaz, [...]" como afirma Plaisance (2015, p. 231). Para o autor, se uma pessoa passasse a ser denominada de "anormal" também poderia ser afastada da sociedade em razão desta "anomalia" e enviada para estabelecimentos "especializados" no atendimento deste público específico.

Na mesma direção, Sassaki (2002) aponta que, no Brasil, o termo mais utilizado para fazer referência a uma pessoa com deficiência, inclusive na legislação, era de "inválido" e cita como exemplo o Decreto federal $n^{\circ} 60.501$, de 14/3/67, que deu nova redação ao Decreto $n^{\circ}$ 48.959-A, de 19/9/60 e falava que "a reabilitação profissional visa a proporcionar aos beneficiários inválidos [...]". Este termo "inválido" denotava que a pessoa com deficiência não tinha "valor" (SASSAKI, 2002, p. 2). De acordo com esse autor, a utilização do termo “inválido" em pleno século XX, não era considerado pelo legislador como pejorativo. Por este prisma, "aquele que tinha deficiência era tido como socialmente inútil, um peso morto para a sociedade, um fardo para a família, alguém sem valor profissional” (SASSAKI, 2002, p. 2).

Com o advento da Associação dos Amigos dos excepcionais - APAE, na década de 1950, em nosso país foi adotada a terminologia "excepcional" que "significava indivíduos com deficiência intelectual" (SASSAKI, 2002, p. 2). 
O ano de 1981, considerado pelas Organizações das Nações Unidas - ONU - como o Ano Internacional das Pessoas Deficientes legitimou “o substantivo 'deficientes' (como em 'os deficientes')" que "passou a ser utilizado como adjetivo, sendo-lhe acrescentado o substantivo “pessoa"”. (SASSAKI, 2002, p.3).

Segundo o autor, os países de língua portuguesa encaminharam proposta com o objetivo de permutar o termo "pessoa com deficiência" por "pessoa portadora de deficiência" e "pela lei de do menor esforço, logo reduziram este termo para 'portadores de deficiência"”. O termo "portadores de deficiência" passou a ser utilizado em todos os documentos de leis e políticas referentes às pessoas com deficiência (SASSAKI, 2002, p. 3).

Outra terminologia que surge para substituir a palavra deficiência é "necessidades especiais", daí surge a expressão "portadores de necessidades especiais". A Resolução CNE/CEB $n^{\circ} 2$, de 11 de setembro de 2001, em seu Artigo 5 $5^{\circ}$, menciona pela primeira vez esse termo que, posteriormente adquire sentido próprio não servindo mais para substituir a palavra deficiência (SASSAKI, 2002, p. 3).

Com a Declaração de Salamanca (1994) ficou estabelecido que todos devem ter acesso à educação, quer seja pessoa com deficiência ou sem deficiência, em igualdade de condições em uma sociedade inclusiva.

A partir da década de 1990, o termo "pessoa com deficiência" é empregado "por um número cada vez maior de adeptos, boa parte dos quais é constituída por pessoas com deficiência” (SASSAKI, 2002, p. 5).

\subsection{Deficiência e o modelo médico ou patológico}

Alguns termos são utilizados com certa frequência por pessoas que, de uma forma ou outra tratam da deficiência, quer seja na condição de pessoa com deficiência, profissionais ligados à área, pesquisadores, enfim, uma infinidade de atores sociais que têm contato com citações em outros idiomas e traduzidas para o português como é caso de: impairment; disability e handicap (AMARAL, 1995, p. 66) que incorporadas ao nosso idioma fazem referência à deficiência; à incapacidade e à desvantagem, respectivamente.

Neste universo chamado deficiência e abordado, inicialmente, sob o ponto de vista do modelo médico ou patológico, observa-se que a primeira Classificação Internacional das Deficiências (CIH) ocorreu no ano de 1980 por atribuição da Organização Mundial de Saúde - OMS. De acordo com Plaisance (2015), o CIH "tinha a vantagem de ter desmembrado a representação simplista e homogeneizante da deficiência, considerando três níveis distintos, 
mas interconectados: A deficiência, a incapacidade, a deficiência no sentido de desvantagem social (PLAISANCE, 2015, p. 233).

No ano de 2001 a classificação foi revista e passou a vigorar a Classificação Internacional de Funcionalidade, Incapacidade e Saúde (CIF). Para Plaisance (2015),

O esquema proposto é mais complexo e mais interativo entre os níveis, que recebem novas denominações em um sentido positivo: funções orgânicas e estruturas anatômicas; atividade; participação. O alcance geral desta classificação é mais ambicioso, pois agora se trata de delimitar, de maneira global, todo o problema de saúde e aplicar essa classificação em nível internacional (PLAISANCE, 2015, p. 233).

Por definição, deficiência corresponde a "toda a alteração do corpo ou aparência física, de um órgão ou de função, qualquer que seja sua causa; em princípio significam perturbações a nível de órgão" (AMARAL, 1995, p. 63). Por suas características, a deficiência envolve as

Perdas ou alterações que podem ser temporárias ou permanentes e que incluem a existência ou ocorrência de uma anomalia, defeito ou perda de um membro, órgão tecido ou outra estrutura do corpo, incluindo a função mental. A deficiência representa a exteriorização de um estado patológico e, em princípio, reflete perturbação a nível de órgão (AMARAL, 1995, p. 63).

Entende-se por incapacidade "as consequências das deficiências em termos de desempenho e atividade funcional do indivíduo; as incapacidades representam perturbações ao nível da própria pessoa" (AMARAL, 1995, p. 63). O indivíduo pode ser considerado incapaz em razão do "excesso ou insuficiência no comportamento ou no desempenho de uma atividade que se tem por comum ou normal” (AMARAL, 1995, p. 63).

Outro aspecto que ser evidenciado é a "desvantagem (handicap), ou seja, esta condição está relacionada à deficiência e a incapacidade; refletem, pois, a adaptação do indivíduo e a interação dele com o meio". Por suas características a desvantagem "refere-se ao valor dado à situação ou à experiência do indivíduo, quando aquele se afasta da norma." Para a compreensão deste item, a desvantagem "representa a expressão social de uma deficiência ou incapacidade, e como tal reflete as consequências - culturais, sociais, econômicas, e ambientais [...]" (AMARAL, 1995, p. 63).

Usando-se a definição e as características próprias das pessoas com deficiência apontadas por Amaral (1995) para abordar a deficiência, faz-se um breve ensaio traçando um paralelo entre a teoria e realidade vivida pelas pessoas com deficiência visual que buscam através dos canais de televisão e da produção cinematográfica o acesso à cultura, à 
informação, à notícia, ao entretenimento, enfim, a todos os produtos audiovisuais oferecidos por estes meios de comunicação.

Verifica-se que a pessoa cega ou com baixa visão possui uma deficiência, no entanto, essa condição não vai incapacitá-la de sentar-se diante da televisão para acompanhar os programas ou caminhar até o cinema para "ver" um filme. Neste caso, a pessoa com deficiência visual vai sentir-se incapacitada de ver as imagens e, com isso, a deficiência caracteriza-se pela ausência de uma tecnologia assistiva de acessibilidade - a AD, e essa falta não permite ou limita sua interpretação e interação com o que acontece na tela. $O$ Decreto 6949/2009 preconiza que a deficiência não está na pessoa e sim na relação dela com o ambiente. Em outras palavras, a pessoa possui uma deficiência visual, mas se o programa ou o filme oferecerem a audiodescrição, a pessoa cega ou com baixa visão passa ter a capacidade de entender qualquer um deles.

Também pode acontecer da pessoa com deficiência visual ficar em desvantagem em relação às demais pessoas, isto é, quando o filme ou programa de televisão não oferecem a audiodescrição.

É possível estabelecer as diferenças se o mesmo quadro fosse visto pelo ponto de vista biomédico que trataria a deficiência visual com base na lesão dos olhos, ou seja, centraria sua atenção na cegueira ou na baixa visão e "nas desvantagens naturais e indesejáveis" como diria Diniz (2009). Na visão de Diniz, seria oferecida ou imposta à pessoa com deficiência a oportunidade de "práticas de reabilitação ou curativas" que poderiam "reverter ou atenuar os sinais da anormalidade" (DINIZ, 2009, p. 68).

\section{Conclusões}

Pelo exposto, é possível inferir que a audiodescrição (AD) constitui-se em elemento fulcral para a inclusão sociocultural das pessoas com deficiência, pois é um recurso de tecnologia Assistiva (TA) que, entre outros atributos, presta-se a ser uma "ponte" que conduz a pessoa com deficiência visual a acessar os conteúdos audiovisuais.

Outro aspecto a ser considerado diz respeito ao arcabouço legal que pode ser utilizado para garantir o direito constitucional das pessoas com deficiência à equidade, ao poderem acessar a informação e a comunicação por outros meios, de modo a alcançar a igualdade de condições com as demais pessoas.

Lembra-se, também, que a partir da promulgação do Decreto nº 6.949/2009 altera-se o entendimento sobre a deficiência, isto é, a deficiência não está na pessoa e sim na relação que esta estabelece com o seu entorno. 
RELACult - Revista Latino-Americana de Estudos em Cultura e Sociedade

Revista Latinoamericana de Estudios en Cultura y Sociedad | Latin American Journal of Studies in Culture and Society V. 03, nº 01, jan-abr., 2017, p. 26-42 | relacult.claec.org e-ISSN 2016/Atual: 2525-7870 | e-ISSN 2015/2016: 2447-018X

Evidencia-se a Norma 01/2006 que trata dos recursos de acessibilidade disponibilizados pelas Emissoras de Televisão, a Instrução Normativa 116/2014 dispõe sobre os projetos audiovisuais financiados pelo governo federal e pela ANCINE e a ABNT 1529/2005 que aborda especificamente a acessibilidade por parte das pessoas com deficiência visual, cegueira ou baixa visão, à programação das Emissoras de Televisão.

\section{Referências}

AMARAL, Lígia Assumpção. Conhecendo a Deficiência (em companhia de Hércules). São Paulo: Robe Editorial, 1995.

ARAÚJO, Luiz A. David. A proteção constitucional das pessoas portadoras de deficiência. Brasília: Coordenadoria Nacional para Integração da Pessoa com Deficiência, 1997.

ASSOCIAÇÃO Brasileira de Normas Técnicas - ABNT NBR 15290. Acessibilidade em Comunicação na Televisão. Rio de Janeiro: ABNT, 2005.

BRASIL. Casa Civil. Lei $n^{\circ} 10.098$, de 19 de dezembro de 2000. Estabelece normas gerais e critérios básicos para a promoção da acessibilidade das pessoas portadoras de deficiência ou com mobilidade reduzida, e dá outras providências. Brasília: Diário Oficial da União, 2000.

BRASIL. Casa Civil. Decreto $N^{o} 5.296$ de 02 de dezembro de 2004. Regulamenta as Leis n 10.048 , de 8 de novembro de 2000 , que dá prioridade de atendimento às pessoas que especifica, e 10.098, de 19 de dezembro de 2000, que estabelece normas gerais e critérios básicos para a promoção da acessibilidade das pessoas portadoras de deficiência ou com mobilidade reduzida, e dá outras providências. Brasília: Diário Oficial da União, 2004.

BRASIL. Ministério das Comunicações. Norma Complementar no 01/2006. Brasília, 2006. Disponível em: http://www.mc.gov.br/documentos/documentos/norma-complementar-n-0126082016.pdf> Acesso em 28 agosto 2016.

BRASIL. Decreto $n^{o}$ 6.949, de 25 de agosto de 2009. Promulga a Convenção Internacional sobre os Direitos das Pessoas com Deficiência - ONU. Brasília: Diário Oficial da União, 2009.

BRASIL. MinC. ANCINE. Instrução Normativa no 116, de 18 de dezembro de 2014. Dispõe sobre as normas gerais e critérios básicos de acessibilidade a serem observados por projetos audiovisuais financiados com recursos públicos federais geridos pela ANCINE; altera as Instruções Normativas $n^{\circ} .22 / 03,44 / 05,61 / 07$ e 80/08, e dá outras providências. Brasília: ANCINE, 2014.

BRASIL. Casa Civil. Lei $n^{o} 13.146$, de 6 de julho de 2015. Institui a Lei Brasileira de Inclusão da Pessoa com Deficiência (Estatuto da Pessoa com Deficiência). Brasília: Diário Oficial da União, 2015. 
DINIZ, Debora; BARBOSA, Lívia; SANTOS, Wederson Rufino dos. Deficiência, Direitos Humanos e Justiça. SUR, v. 6, n. 11, p. 65-77, dez. 2009.

FILHO, P. R. Políticas Públicas de Acessibilidade para Pessoas com Deficiência Audiodescrição na Televisão Brasileira. In. MOTTA, Lívia Maria Villela de Mello; FILHO, Paulo Romeu. Orgs. Audiodescrição: transformando imagens em palavra. São Paulo:

Secretaria dos Direitos da Pessoa com Deficiência do Estado de São Paulo, 2010. Disponível em <file:///F:/Obras/LIVRO_AUDIODESCRICAO_TRANSFORMANDO_IMAGENS_EM_PA LAVRAS.pdf>. Acesso em 19 Ago. 2016.

FRANCO, Eliana P. Cardoso; SILVA, Manoela C. C. C. da. Audiodescrição: Breve Passeio Histórico. In: MOTTA, Lívia Maria Villela de Mello; FILHO, Paulo Romeu. Orgs. Audiodescrição: transformando imagens em palavra. São Paulo: Secretaria dos Direitos da Pessoa com Deficiência do Estado de São Paulo, 2010. Disponível em <file:///F:/Obras/LIVRO_AUDIODESCRICAO_TRANSFORMANDO_IMAGENS_EM_PA LAVRAS.pdf $>$. Acesso em 19 Ago. 2016.

JÚNIOR, Juarez N. de Oliveira; FILHO, Pedro H. L. Praxedes. A (não) neutralidade em roteiros de audiodescrição-ad de filmes de curta metragem via sistema de avaliatividade. In: CARPES, Daiana Stockey. Org. Audiodescrição: práticas e reflexões [recurso eletrônico]. 1. ed. Santa Cruz do Sul: Catarse, 2016. p. 22-36.

JAKOBSON, Roman. Linguística e Comunicação. 24. ed. Trad. Izidoro Blikstein e José Paulo Paes. São Paulo: Cultrix, 2007.

LANNA JÚNIOR, Mário Cléber Martins. História do Movimento Político das Pessoas com Deficiência no Brasil. Brasília: SDH/SNPDPD, 2010.

OLIVEIRA, Luiza Maria Borges de. Cartilha do Censo 2010. Pessoas com Deficiência. Brasília: SDH-PR/SNPD, 2012. Disponível em:

http://www.pessoacomdeficiencia.gov.br/app/sites/default/files/publicacoes/cartilha-censo2010-pessoas-com-deficienciareduzido.pdf. Acesso em: 28 agosto 2016.

PEIRCE, C. S. Semiótica. Trad. José Teixeira Coelho Neto. São Paulo: Perspectiva, 2000.

PLAISANCE, ERICK. Da educação especial à educação inclusiva: esclarecendo as palavras para definir as práticas. Trad. Patrícia Reuillard. Educação (Porto Alegre, impresso), v. 38, nº 2, p. 230-238, maio-ago. 2015.

PLAZA, Julio. Tradução intersemiótica. $1^{\text {a }}$ ed. São Paulo: Perspectiva, 2008.

SANTAELLA, Lucia; NÖTH, Winfried. Imagem: cognição, semiótica, mídia. 4. ed. São Paulo: Iluminuras, 2005.

. Matrizes da linguagem e pensamento: sonora visual verbal: Aplicações na hipermídia.

3 ed. São Paulo: Iluminuras FAPESP, 2005.

O que é semiótica. São Paulo: Brasiliense, 2012. 
RELACult - Revista Latino-Americana de Estudos em Cultura e Sociedade

Revista Latinoamericana de Estudios en Cultura y Sociedad | Latin American Journal of Studies in Culture and Society V. 03, no 01, jan-abr., 2017, p. 26-42 | relacult.claec.org e-ISSN 2016/Atual: 2525-7870 | e-ISSN 2015/2016: 2447-018X

SASSAKI, Romeu Kazumi. Inclusão: Construindo uma sociedade para todos. - Rio de Janeiro; WVA, 1997.

Terminologia sobre deficiência na era da inclusão. Revista Nacional de Reabilitação, ano 5. n. 24. Jan/fev. 2002. P. 6-9. 